\title{
Would decriminalising personal use of cannabis lead to higher rates of mental illness?
}

H Valerie Curran, ${ }^{4}$ director, Clinical Psychopharmacology Unit and professor of psychopharmacology; Niamh Eastwood, ${ }^{5}$ Executive Director Release; Adam R Winstock, ${ }^{6}$ founder and chief executive officer, Global Drug Survey, and honorary clinical professor, Department of Epidemiology

${ }^{4}$ University College London

${ }^{5}$ Release, London

${ }^{6}$ University College London

Correspondence to: H V Curran v.curran@ucl.ac.uk

Removing criminal penalties for possession could increase adolescent use, say Bobby $\boldsymbol{P}$ Smyth, Mary Cannon, and Andrew Molodynski. But H Valerie Curran, Niamh Eastwood, and Adam $\boldsymbol{R}$ Winstock find no evidence for this and say that liberalisation of drug laws could reduce harms

\section{No-H Valerie Curran, Niamh Eastwood, Adam Winstock}

The causes of mental illness in a society are multifactorial, with risks linked to inequality, socioeconomic deprivation, and poor physical health. Regular use of drugs such as cannabis and alcohol can exacerbate pre-existing mental illness and worsen outcomes.

The vast majority of people who use cannabis do so for a limited time (often from adolescence to mid-20s) and experience few mental health consequences, if any. A minority do experience problems, and around $9 \%$ become dependent on the drug - a lower rate than dependence on alcohol (22\%) or nicotine (67\%). ${ }^{1}$ Experts have rated cannabis 11 th of 20 commonly used recreational drugs for its dependence-inducing effects as well as its general harms to individuals and society, well behind alcohol and nicotine.. ${ }^{2}$ Frequent cannabis use has also been associated with psychosis in people who are vulnerable from genetic, environmental, or childhood adversity factors. ${ }^{3}$

\section{Potency matters}

The type of cannabis used is critical to mental health. High potency varieties - rich in tetrahydrocannabinol (THC) and very low in cannabidiol (CBD) - are associated with increased rates of dependence and treatment seeking. ${ }^{4}$ Strains containing $>10 \%$ THC may increase the probability of psychotic disorder among predisposed young people, whereas strains with $<10 \%$ may not .5

Cannabis containing THC but negligible CBD (unlike balanced strains) can also increase psychosis-like symptoms in healthy people ${ }^{6}$. Although depression and anxiety are often comorbid with cannabis dependence in daily users, causality is weak and complex ${ }^{3,4}$ Indeed, 
the biggest risk that cannabis use poses to mental health is the exacerbation of pre-existing mental illness, not its de novo development.

\section{Decriminalisation versus prohibition}

Currently in the UK, cannabis is prohibited for recreational use but can be legally prescribed for limited medicinal purposes. Decriminalisation would remove criminal sanctions for possessing small quantities for personal use. Civil penalties, including fines or referral to a drug awareness course, could be given but without the person acquiring a criminal record. Such a move could have beneficial effects on mental health, because a criminal record stigmatises and can impinge adversely on employment, relationships, and travel all of which can contribute to negative health outcomes. ${ }^{7}$ As heavy cannabis use can be associated with lower educational achievement, unemployment and lower income, what society would wish to compound these disadvantages further with criminalisation?

Decriminalisation has been associated with better health and social outcomes and reduced (re)offending among people caught in possession of cannabis, suggesting that decriminalisation would be positive for drug users' mental health and general wellbeing. ${ }^{8}$ Decriminalisation may also reduce barriers to users seeking help and engaging with health services. ${ }^{9}$

Criminalisation of cannabis, in particular possession offences, affects police-community relations: UK black people were searched for drugs nine times more than white people in 2016-17 ${ }^{8}$, despite government data showing that black people are less likely to use cannabis than the white population ${ }^{10}$. And prohibition is expensive. Cannabis use represents $80 \%$ of all illicit drug use, and drug stop-and-searches, driven largely by cannabis possession, account for 60 per cent of all police searches ${ }^{8}$. So the costs of policing alone are vast and could be more helpfully invested in prevention, , harm reduction and youth social initiatives.

Because early first use can increase the risk of mental health problems ${ }^{4}$, potential effects of decriminalisation on adolescents are of particular concern. . A reanalysis of the WHO Collaborative Cross-National Survey ${ }^{11}$ compared 18 countries that had maintained cannabis prohibition from 2001 to 2010 with 20 countries that had more liberal policies (11 had decriminalised cannabis). No association was found linking "liberalisation" with higher odds of adolescent cannabis use: similar findings to a study comparing US states that had and had not legalised the supply of cannabis. ${ }^{12}$ If rates of use do not increase among adolescents, as the evidence suggests, neither should mental illness. Indeed, in Europe, no consistent effect 
on rates of cannabis use in the general population has been observed after either reductions or increases in penalties for possessing cannabis. ${ }^{13}$

\section{State control is healthiest}

Drug policies are complex, with multiple components and consequences. Mental health and criminology experts recently evaluated four different cannabis policies in terms of their consequences on seven criteria, including health promotion, public wellbeing, social factors, crime reduction, and cost. ${ }^{14}$ This ranked state control of supply as the most beneficial policy, free market supply second, decriminalisation of use alone with illegal supply third, and prohibition last, in terms of beneficial consequences.

The experts concluded that state control of cannabis markets could have major public health benefits in providing cannabis varieties with lower THC and higher CBD content to reduce rates of drug dependence and possibly psychosis. Age controls and harm reduction advice given at purchase could also reduce adverse consequences associated with the current mass diversification of potent cannabis products (such as edibles, oils, and concentrates), However, decriminalisation of people who use cannabis may need to be the first step in liberalising cannabis policy in the UK. Decriminalisation would allow the culture and conversation around drug use in the UK to change from zero tolerance to harm reduction. Reduced stigma would support earlier help seeking. The question is not whether decriminalisation would lead to more people using cannabis but whether it would lead to overall worse population health outcomes. We suggest the evidence strongly supports our view that it would not.

Competing interests: We have read and understood BMJ policy on declaration of interests and have no relevant interests to declare. No author has taken funding from the alcohol, tobacco or cannabis industry.[OK?]

Provenance and peer review: Commissioned; externally peer reviewed.

1 Lopez-Quintero C, de los Cobos JP, Hasin DS, et al. Probability and predictors of transition from first use to dependence on nicotine, alcohol, cannabis, and cocaine: results of the National Epidemiologic Survey on Alcohol and Related Conditions (NESARC). Drug Alcohol Depend 2011;115:120-30.

2 Nutt D, King LA, Saulsbury W, Blakemore C. Development of a rational scale to assess the harm of drugs of potential misuse. Lancet 2007;369:1047-53.

3 Gage SH, Hickman M, Zammit S. Association between cannabis and psychosis: epidemiologic evidence. Biol Psychiatry 2016;79:549-56.

4 Curran HV, Freeman TP, Mokrysz C, Lewis DA, Morgan CJ, Parsons LH. Keep off the grass? Cannabis, cognition and addiction. Nat Rev Neurosci 2016;17:293-306. 
5 Di Forti M, Quattrone D, Freeman TP, et al. The contribution of cannabis use to variation in the incidence of psychotic disorder across Europe (EU-GEI): a multicentre case-control study. Lancet Psychiatry 2019;6:427-36.

6 Morgan \& Curran, Effects of cannabidiol on schizophrenia-like symptoms in people who use cannabis. Br J Psychiatry 2008;192,306-7.

7 Van den Brink W. Forum: decriminalization of cannabis. Curr Opin Psychiatry 2008;21:122-6.

8 Shiner M, Carre Z, Delsol R, Eastwood N. The colour of injustice: race, drugs and law enforcement in England and Wales. 2018.

https://www.release.org.uk/publications/ColourOfInjustice

9 Benfer I, Zahnow R, Barratt MJ, Maier L, Winstock A, Ferris J. The impact of drug policy liberalisation on willingness to seek help for problem drug use: A comparison of 20 countries. Int J Drug Policy 2018;56:162-75.

10. Home Office, Drug Misuse Findings from the Crime Survey of England and Wales 2018 - 2019, Table 3.01 https://www.gov.uk/government/statistics/drug-misuse-findings-from-the2018-to-2019-csew

11 Stevens A. Is policy "liberalisation" associated with higher odds of adolescent cannabis use? A re-analysis of data from 38 countries. Int J Drug Policy 2019;66:94-9.

12 Grucza R, Vuolo M, Krauss M, et al. Cannabis decriminalization: a study of recent policy change in five US states. Int J Drug Policy 2018;59:67-75.

13 Hughes B, Matias J, Griffiths P. Inconsistencies in the assumptions linking punitive sanctions and use of cannabis and new psychoactive substances in Europe. Addiction 2018;113: 2155-7.

14 Rogberg O, Bergsvika D, Phillips LD, et al. A new approach to formulating and appraising drug policy: A multi-criterion decision analysis applied to alcohol and cannabis regulation. Int J Drug Policy 2018;56:144-52. 